\title{
Experimental syphilis in the chimpanzee Immunoglobulin class of early antibodies reactive with Treponema pallidum
}

\author{
W. J. BROWN, U. S. G. KUHN, E. A. TOLLIVER, AND L. C. NORINS \\ Venereal Disease Research Laboratory, Venereal Disease Branch, State and Community Services Division, \\ National Communicable Disease Center, Health Services and Mental Health Administration, \\ Public Health Service, U.S. Department of Health, Education, and Welfare, Atlanta, Georgia 30333, U.S.A.
}

Previous studies in this laboratory of experimental syphilis in chimpanzees have established that the Fluorescent Treponemal Antibody-Absorption (FTAABS) test and other serological tests for syphilis become reactive after inoculation with Treponema pallidum (Kuhn, Brown, and Cox, in preparation). Samples of chimpanzee sera collected before inoculation and at regular intervals thereafter were available from these investigations. In the present study we used monospecific fluorescent antibody (FA) reagents to identify the immunoglobulins operative in the FTA-ABS test reactivity which developed following infection.

\section{Material and methods}

Six juvenile chimpanzees (Pan trogolodytes), 2 to 4 years old, were infected with a strain of $T$. pallidum which was originally obtained from a human syphilitic lesion. Details of inoculation and the handling of the animals are presented elsewhere (Kuhn and others, in preparation).

The chimpanzees at this laboratory were kept from 8 to 10 months before inoculation, and at no time did they receive antibiotics. Upon arrival, six of twelve animals were reactive in one or more treponemal tests. Based on the FTA-ABS and Treponema pallidum Immobilization (TPI) tests before inoculation, we divided the animals into two groups, as shown in the Table. Chimpanzees 1,2 , and 3 were selected for use as a 'sero-negative' group because, on two occasions before inoculation, they were nonreactive in the VDRL Slide, FTA-ABS, and TPI tests. Chimpanzees 4, 5, and 6 were selected as a 'sero-positive' group because, before inoculation, they were reactive in one or more of the test procedures. However, in serum taken at the time of inoculation, chimpanzees 2 and 3 were unexpectedly weakly reactive and reactive in the TPI test but not in the other tests. This report of un-

Received for publication August 5, 1969

Trade names are used for identification only and do not represent an endorsement by the Public Health Service or the U.S. Department of Health, Education, and Welfare.

*Presented, in part, at the Fourth Joint Meeting of the Clinical Society and Commissioned Officers' Association, Boston, Mass., June 2-5 1969.
TABLE First indication of syphilis infection after inoculation of Treponema pallidum into chimpanzees

\begin{tabular}{|c|c|c|c|c|c|c|}
\hline \multirow{3}{*}{$\begin{array}{l}\text { Chimpanzee } \\
\text { No. }\end{array}$} & \multirow{3}{*}{$\begin{array}{l}\text { Positive } \\
\text { darkfield } \\
\text { examinationt }\end{array}$} & \multicolumn{5}{|c|}{ Tests on whole serum } \\
\hline & & \multicolumn{3}{|c|}{$F T A-A B S$} & \multirow{2}{*}{$\begin{array}{l}V D R L \\
\text { slide }\end{array}$} & \multirow[t]{2}{*}{$T P I$} \\
\hline & & $I g M^{\star}$ & $\operatorname{Ig} G$ & $\operatorname{Ig} A$ & & \\
\hline $\begin{array}{l}1 \\
2 \\
3\end{array}$ & $\begin{array}{l}14 \\
27 \\
14\end{array}$ & $\begin{array}{l}14 \\
21 \\
14\end{array}$ & $\begin{array}{l}14 \\
21 \\
21\end{array}$ & $\begin{array}{l}14 \ddagger \\
N \\
21\end{array}$ & $\begin{array}{l}35 \\
49 \\
21\end{array}$ & $\begin{array}{l}42 \\
\text { PR } \\
\text { PR }\end{array}$ \\
\hline $\begin{array}{l}4 \\
5 \\
6\end{array}$ & $\begin{array}{l}21 \\
N \\
N\end{array}$ & $\begin{array}{l}21 \\
\text { PR } \\
\text { PR }\end{array}$ & $\begin{array}{l}\text { PR } \\
\text { PR } \\
\text { PR }\end{array}$ & $\begin{array}{l}\mathbf{N} \\
\mathbf{P R} \\
\mathbf{N}\end{array}$ & $\begin{array}{l}14 \\
7 \\
\text { PR }\end{array}$ & $\begin{array}{l}21 \\
7 \\
\text { PR }\end{array}$ \\
\hline
\end{tabular}

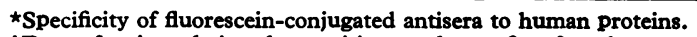
†Days after inoculation that positive result was first found. ¥Trace reactivity only.

N-Positive result was not found at any time.

PR-Reactivity found in serum taken before inoculation.

expected reactivity was received after the experimental inoculations had been made. The significance of this report of isolated TPI reactivity is uncertain and has been seen in a few other chimpanzees (Kuhn, Brown, and Falcone, 1968), and in a small number of humans (Deacon, Lucas, and Price, 1966). Although practical considerations required us to continue the experimental groups as planned, the isolated report of TPI reactivity should be kept in mind as a possible influence on the results we observed.

The first chimpanzee to be infected (No. 1) was inoculated in the skin of the back with darkfield-positive serous material from a human primary syphilitic lesion. From the lesion which developed, the other five chimpanzees were, in turn, infected by inoculation of infectious material into the skin at the base of the penis or into the left lip of the vulva.

The animals were bled before inoculation and approximately every 7 days thereafter. Inoculation sites were observed daily, and darkfield examinations were performed at intervals of approximately 7 days on lesions which developed at inoculation sites.

Sera were separated and stored in sterile vials at $-20^{\circ} \mathrm{C}$. until use. The sera were then thawed and coded to disguise 
their identity, and samples were subjected to gel filtration at $4^{\circ} \mathrm{C}$. on a $2 \cdot 5-\times 90-\mathrm{cm}$. column of Sephadex G-200', using the technique of Flodin and Killander (1962), as modified by Julian, Logan, and Norins (1969). In brief, 3 to $5 \mathrm{ml}$. samples of serum previously equilibrated with $0.1 \mathrm{M}$ Tris buffer, plus $1 \mathrm{M}$ sodium chloride, were placed in the bottom of the column. Upward flow elution was carried out with the same buffer. The elute fractions comprising the ' $19 \mathrm{~S}$ ', '7 S', and ' $3.5 \mathrm{~S}$ ', peaks and the '9-11 $S$ ' and '5 $S$ ' troughs were pooled, concentrated to $1 \mathrm{ml}$. each, and dialysed against phosphatebuffered saline (PBS) before testing.

Each serum, and its various pooled fractions, was tested for the presence of antibodies reactive with $T$. pallidum by using each of three FA conjugates in an FTA-ABS procedure (Venereal Disease Research Laboratory, 1968). Fluorescein-conjugated monospecific antisera to human IgG, IgA, and $\operatorname{IgM}^{2}$ were used to reveal the class of chimpanzee immunoglobulins reactive with $T$. pallidum. Detailed evidence that these reagents are monospecific against the various human immunoglobulins has been presented previously (Julian and others, 1969). Each of these conjugates, when tested undiluted, formed a single precipitin line in gel diffusion against chimpanzee serum, and this line gave a reaction of identity with the line produced by the same conjugate against human serum. Each lot of tests included appropriate positive and negative controls. An arbitrary scale ranging from negative to $4+$ was used to score the degiees of fluorescence, with $1+$ as the least intensity considered reactive. Samples and slides were coded before being tested, and all scored by the same observer. Sera and serum fractions from all of the bleeding dates of any one animal were always tested on a single day. A single lot of antigen and of sorbent was used throughout the study. In this report, the specific FA conjugate used in the FTA-ABS procedure is denoted in parentheses following the test abbreviation; e.g. FTA-ABS (IgM), etc.

\section{Results}

Preinoculation sera from three of the six chimpanzees $(1,2$, and 3$)$ showed no FTA-ABS reactivity with antiIgG, anti-IgM, or anti-IgA conjugates; therefore, particular attention was paid to the results obtained in these animals. After inoculation, all three of these chimpanzees developed darkfield-positive lesions and reactivity in several assays (Table).

In chimpanzees 1 and 2, FTA-ABS (IgM) and FTA-ABS (IgG) reactivity was found concurrently; by 14 days in 1 and by 21 days in 2 . In chimpanzee 3 , IgM reactivity was found at 14 days, 7 days before IgG reactivity.

The FTA-ABS (IgM) assay became reactive from 7 to 28 days before the VDRL Slide test reactivity appeared. In two of three instances (1 and 2), the

'Pharmacia Fine Chemicals, Inc., Piscataway, N.J.

'Hyland, Division Travenol Laboratories, Inc., Los Angeles, Calif.
FTA-ABS (IgG) became reactive 21 to 28 days before the VDRL slide test, and in one instance (3) the two procedures became reactive at the same time.

In chimpanzee 1, FTA-ABS (IgM) and FTAABS (IgG) reactivities were found concurrently with the detection of a darkfield-positive lesion. At 21 days in No. 2, both FTA-ABS (IgM) and FTA-ABS (IgG) were found, and an erythematous papule was noted at the inoculation site. Though it was felt that the papule might well be darkfield-positive, it was decided not to perform a darkfield examination at that point in order to avoid disturbing the evolution of the lesion; 6 days later (27 days) the lesion had opened, and a positive darkfield examination was obtained on the serous fluid which could be readily expressed with gentle pressure. In chimpanzee 3, FTA-ABS (IgM) reactivity was found at the same time as was the darkfield-positive lesion, but FTAABS (IgG) reactivity was not found until 7 days later.

In contrast to the immunofluorescence findings, VDRL slide test reactivity was not found until 21 days (1), 22 days (2), or 7 days (3) after the inoculation site was determined to be darkfield positive.

Preinoculation serum from the three other chimpanzees (4, 5, and 6) showed FTA-ABS (IgG) reactivity, and two of these sera (5 and 6) also showed FTA-ABS (IgM) reactivity. These reactions continued to be present after inoculation. These two primates (5 and 6) never developed a darkfield lesion at the site of inoculation. No. 4, with pre-existing IgG, but not IgM, reactivity, developed a darkfield lesion by 21 days after inoculation, and began to show FTA-ABS (IgM) reactivity at the same time.

The FTA-ABS (IgM) fluorescence was usually less intense than the FTA-ABS (IgG) fluorescence. The FTA-ABS (IgA) reactivity in whole serum and fractions never achieved more than trace levels, which appeared by days 14 and 21 in Nos. 1 and 3 .

Throughout this study, the immunofluorescence testing of serum fractions always confirmed any reactivity found in whole serum. Serum fractions never showed reactivity that had not been seen in the whole serum. In a few instances, however, weak IgA or IgM reactivity was seen in a whole serum, but the relevant reactivity could not be found in any of its fractions. Comparison of the immunoglobulin concentration in whole serum and the derived fractions revealed that there had been a low percentage recovery of immunoglobulins in those particular separations.

\section{Discussion}

Scarcity, high cost, and other practical considerations limit the number of chimpanzees that may be used for 
any one experimental study. Nevertheless, the phylogenetic proximity of the great apes to man, as expressed in morphological and immunochemical terms, suggest the significance of the data obtained from this animal model in the study of human disease. We endeavoured, through regular and intensive observation of an admittedly small number of chimpanzees, to gather information not usually available in the human clinical situation.

Our data on these six chimpanzees show that, when conjugates of appropriate specificity were used, an FTA-ABS procedure could detect immunoglobulins reactive with $T$. pallidum in serum and serum fractions, at approximately the same time as the appearance of a darkfield-positive lesion, and as much as 28 days before VDRL test reactivity appeared. In two of three animals with non-reactive FTA-ABS tests before inoculation, both IgM and IgG antibodies were found in the initially detected immunofluorescent activity, while IgM reactivity was found earlier than IgG in the third. This demonstration that IgM and IgG antibodies to $T$. pallidum may appear significantly in advance of antibodies to cardiolipin shows an interesting parallel to the finding that about 86 per cent. of patients with untreated primary syphilis are reactive in the FTA-ABS test, but that only about 76 per cent. are reactive in the VDRL slide test (Deacon and others, 1966). The results also parallel the finding that both FTA-ABS (IgM) and FTA-ABS (IgG) reactivity are found in humans with primary or secondary syphilis (Julian and others, 1969).

Even though there are numerous biological similarities between chimpanzees and humans, there are several obvious points to be kept in mind in deciding to what extent the results of this study apply to human syphilis patients. For example, it is uncertain as to what extent the site of inoculation and size of inoculum reproduce the human situation.

Also, we cannot rigorously establish the history of the chimpanzee with regard to previous treponemal infection. In a serological survey of 250 chimpanzees in the United States (Kuhn and others, 1968), it was found that 10 per cent. were reactive in the VDRL slide test, 16.4 per cent. in the TPI test, and 15.6 per cent. in the FTA-ABS test. The cause of the reactivity is unknown, but it suggests that there is an enzootic treponematosis which affects a proportion of chimpanzees. Because practical considerations required the use of chimpanzees that were supplied by the animal dealer, we call attention to the unexplained preinoculation TPI reactivity in chimpanzees 2,3 , and 6 , since it might in some unknown way have influenced the time of appearance or the class of the immunoglobulin response we measured.

\section{Summary}

Sera were obtained at regular intervals from chimpanzees after inoculation with $T$. pallidum. By using monospecific fluorescent antisera in an FTA-ABS procedure, it was possible to determine the immunoglobulin class of the anti- $T$. pallidum reactivity which developed. In two of three animals, both IgG and IgM antibodies were found in the initially detected immunofluorescence reactivity, while in the third, IgM was found earlier than IgG reactivity. When conjugates specific for appropriate immunoglobulins were used, the FTA-ABS procedure could detect anti- $T$. pallidum reactivity at approximately the same time as the appearance of a darkfield-positive lesion, and as much as $\mathbf{2 8}$ days before a routine cardiolipin antigen test became reactive.

\section{References}

Deacon, W. E., Lucas, J. B., and Price, E. V. (1966) $\mathcal{F}$. Amer. med. Ass., 198, 624

Flodin, P., and KILLANDER, J. (1962) Biochim. Biophys. Acta, 63, 403

Julian, A. J., Logan, L. C., and Norins, L. C. (1969) f. Immunol., 102, 1250

KunN, U. S. G., Brown, W. J., and Cox, P. M. (1970) In preparation

- L, and FaLcone, V. H. (1968) WHO/VDT/ RES/68.137

VenEREAL Disease Research Laboratory (1968) Hlth Lab. Sci., 5, 23

Syphilis expérimentale du chimpanzé. Catégorie des immunoglobulines des anticorps réagis sant avec Treponema pallidum

SOMMAIRE

Des échantillons de sérum furent prélevés à intervalles réguliers chez des chimpanzés après leur inoculation par T. pallidum. En employant des antisérums fluorescents, monospécifiques, dans la technique d'un FTA-ABS, il a été possible de déterminer les catégories d'immunoglobulines responsables de la réactivité anti $T$. pallidum qui s'était constituée. Chez deux, parmi trois animaux, des anticorps IgG et IgM furent à la fois trouvés, dès le début de la positivité de l'immunofluorescence, alors que chez le troisième primate la positivité $\operatorname{IgM}$ a été détectée plus tôt que la réactivité IgG. En utilisant des conjugués spécifiques pour les immunoglobulines appropriées, la technique FTA-ABS peut détecter une positivité anti $T$. pallidum à peu près en même temps qu'apparaît une lésion positive au fond noir, et ceci jusqu'à 18 jours avant que l'épreuve de routine à l'antigène cardio-lipidique ne devienne positive. 